\title{
La llegada de la peste al Estado de Sao Paulo en 1899
}

\section{Dilene Raimundo do Nascimento $\left(^{*}\right)$}

(*) Casa de Oswaldo Cruz/Fundação Oswaldo Cruz (Brasil).dilene@coc.fiocruz.br

Dynamis

[0211-9536] 2011; $31(1): 65-83$
Fecha de recepción: 2 de febrero de 2010

Fecha de aceptación: 4 de enero de 2011

SUMARIO: 1.-Introducción. 2.-La peste se aproxima a Brasil. 3.-El puerto de Santos. 4.-La peste llega a Brasil. 5.-Las investigaciones de los representantes de DGSP. 6.-La peste en Sao Paulo. 7.-Comentarios finales.

RESUMEN: En octubre de 1899, la peste bubónica llegó a Brasil, por el puerto de Santos. Ciudad paulista de intenso flujo portuario fue la puerta de entrada de la epidemia de peste que asoló varias ciudades brasileñas a comienzos del siglo XX. Esta epidemia fue propulsora de una acción conjunta de varios estados para combatirla $y$, más que eso, ante las dificultades de importación de suero preparado en Europa, llevó a la creación, en 1899, del Instituto Butantan en Sao Paulo, y, en 1900, del Instituto Soroterápico Municipal, en Río de Janeiro. Ambas instituciones fomentaron la elaboración de sueros y vacunas contra la peste estableciendo un patrón de estos productos según las condiciones del país. Las medidas de salud pública desarrolladas hasta entonces se habían aplicado de forma aislada y puntual en Brasil. El doctor Oswaldo Cruz, tras tres años de especialización en el Instituto Pasteur de Paris trabajó en la identificación de la peste en Santos, juntamente con los científicos Adolfo Lutz y Vital Brazil. Este artículo pretende analizar la llegada de la epidemia de peste bubónica al estado de Sao Paulo y las acciones llevadas a cabo en el campo de la salud pública para combate de la enfermedad y la asistencia a los enfermos, especialmente en los primeros años del siglo XX. Las fuentes principales para este análisis son los periódicos paulistas, concretamente O Estado de São Paulo, los informes del Ministerio de Justicia y los mensajes elaborados por el presidente del estado de Sao Paulo.

PALABRAS CLAVE: Epidemia, peste, salud pública, Sao Paulo, Brasil.

KEY WORDS: Epidemic, plague, public health, São Paulo, Brazil.

\section{Introducción}

Este artículo pretende analizar la llegada de la epidemia de peste bubónica al Estado de Sao Paulo en el cambio del siglo XIX al XX y las iniciativas sanitarias para combatir la enfermedad y proporcionar asistencia a las per- 
sonas enfermas. Las fuentes principales para este análisis son los informes del Ministerio de Justicia y Negocios Interiores, los mensajes del presidente del estado de Sao Paulo ${ }^{1}$ y los periódicos paulistas, especialmente $O$ Estado de São Paulo.

La peste bubónica es una enfermedad conocida hace mucho tiempo por la humanidad. Con epidemias recurrentes desde la antigüedad, la peste diezmó a grandes poblaciones, produciendo efectos demográficos, políticos, culturales y religiosos inconmensurables ${ }^{2}$.

Aquello que la historia registra como la Peste Negra, que asoló Europa desde 1348 hasta 1351, es objeto de descripción detallada en la obra Decamerón de Giovanni Boccaccio. El gran escritor italiano, en su detallado relato de la peste en Florencia, organiza de forma armónica perspectivas diferentes para el mismo evento. Así, simultáneamente, en un testimonio hasta hoy válido desde el punto de vista científico de sintomatología de la enfermedad, se lee en el Decamerón una descripción literaria muy elaborada de los horrores causados por la catástrofe. Boccaccio describe así los síntomas:

«Aparecieron al principio, tanto en hombres como en mujeres, o en la ingle o en las axilas, algunas inflamaciones. Algunos crecían como manzanas, otras como un huevo, crecían unas más, otras menos, los populares las llamaban bubones. De estas dos partes referidas del cuerpo, luego el tal tumor tan letal pasaba a repuntar y surgir por todas las partes. Enseguida el aspecto de la enfermedad comenzó a cambiar, empezó a poner manchas negras o lívidas en los enfermos. Estas manchas estaban en los brazos, en los muslos y otras partes del cuerpo. En algunas personas, las manchas aparecían grandes y esparcidas; en otras eran pequeñas y abundantes. Y, del mismo modo como, al principio, el bubón fuera y aún era signo inevitable de muerte futura, las manchas pasaron a ser mortales, después, para los que las tenía» ${ }^{3}$.

Boccaccio prosigue relatando que una de las mayores dificultades era darle sepultura a los muertos:

1. Los mensajes presidenciales, sean del presidente de la República, sean de los presidentes de los estados federativos, representan una síntesis de las expectativas y proposiciones oficiales relativas a las varias áreas de responsabilidad concernientes a los cargos.

2. Delumeau, Jean. História do Medo no Ocidente. São Paulo: Companhia das Letras; 1989, p. 107.

3. Boccaccio, Giovanni. Decamerão. São Paulo: Abril Cultural; 1970, p. 14. 
«Para dar sepultura al gran número de cuerpos ya no era suficiente la tierra sagrada junto a las iglesias; por eso se pasó a edificar iglesias en los cementerios; se ponían en esas iglesias, por centenas, los cadáveres que iban llegando; y eran apilados como las mercancías en los buques» ${ }^{4}$.

Los relatos históricos sobre esa epidemia del siglo XIV, como el de Giovanni Boccaccio, describen siempre un cuadro de terror y ansiedad de las poblaciones frente a un mal a principio incomprensible. A partir de allí, el Occidente heredó, como respuesta de las mentalidades colectivas, la designación de peste como representación de cualquier molestia devastadora. El poder de esa epidemia en el imaginario colectivo europeo no estaba asociado solamente a su cobertura geográfica, sino, principalmente, a su letalidad. Según Delumeau ${ }^{5}$, las fuentes sobre el periodo calculan el total de muertos por la enfermedad en alrededor de un tercio de la población del continente. Esa proporción, sin embargo, fue mayor en algunas localidades, existiendo casos extremos donde el 95\% de la población murió a causa de la peste. Europa conoció otros momentos en los que la peste cobró un gran número de vidas. Según Defoe ${ }^{6}$, la enfermedad atacó Londres en 1665, matando cerca de 68.500 personas. En 1720, en Marsella, mató a unos 50.000. Después de esta gran epidemia, la peste desapareció de Europa, quedando limitada al Oriente, especialmente a India y China ${ }^{7}$.

En 1899, la peste volvió a Europa, específicamente la ciudad de Oporto, Portugal, originaria probablemente de la India. En el mismo año, la plaga llegó por primera vez en América del Sur, a Paraguay. La aparición de la peste en estos países generó el temor en las autoridades brasileñas de que la enfermedad llegaría a Brasil debido a la proximidad geográfica y al gran flujo de comercio y personas entre estos países ${ }^{8}$.

El conocimiento sobre la enfermedad había avanzado y la bacteriología, área de reciente conocimiento, se colocaba como la herramienta adecuada para hacer frente a la enfermedad. Causada por la bacteria Pasteurella pestis,

\footnotetext{
4. Boccaccio, n. 3, p. 18.

5. Delumeuau, n. 2, p. 107.

6. Defoe, Daniel. Um diário do ano da peste. Traducción de Eduardo Serrano San Martin. Porto Alegre: L\&PM; 1987.

7. Delumeau, n. 2, p. 108.

8. Mensaje presentado al presidente de la República de los Estados Unidos de Brasil por el Dr. Epitácio Pessôa, Ministro de Justicia y Negocios Interiores, en marzo de 1900, Río de Janeiro; Imprensa Nacional, p. 350.
} 
la peste se transmite a los humanos por la picadura de pulgas infectadas con sangre de ratas pestosas. En 1906, Oswaldo $\mathrm{Cruz}^{9}$, al enumerar los principales síntomas de la enfermedad, corrobora la descripción de Boccaccio en 1348: fiebre alta, sed intensa y cansancio, después de unos días, aparece la buba, causada por la inflamación de los ganglios linfáticos, siendo esa la principal característica de la enfermedad. Sin tratamiento, la mayoría de las veces, se rompe la buba, lo que lleva al paciente a la muerte. En algunos casos, la enfermedad evoluciona a la forma neumónica o septicémica, más letal y más fácilmente transmisible.

El miedo de la llegada de la peste a Brasil se confirmó cuando, en octubre de 1899, la peste bubónica apareció en el puerto de Santos. El segundo puerto en importancia en el país, Santos fue la puerta de entrada de la epidemia de peste que asoló varias ciudades brasileñas en el siglo XX. Esta epidemia fue propulsora de una acción conjunta de varios estados para combatirla y, más importante, dadas las dificultades de importación de suero preparado de Europa, llevó en 1899 a la creación del Instituto Butantan, en Sao Paulo y, en 1900, a la creación del Instituto Sueroterápico Municipal de Río de Janeiro, ambos con la finalidad de desarrollar sueros y vacunas contra pestes y de establecer una estandarización de estos productos de acuerdo con las condiciones del país. Hasta entonces, en Brasil, las acciones en el ámbito de la salud pública se daban de forma aislada y puntual. Oswaldo Cruz, recién llegado desde el Instituto Pasteur de París después de tres años de especialización, trabajó en la identificación de la peste en Santos junto con los científicos Adolfo Lutz y Vital Brasil ${ }^{10}$.

\section{La peste se aproxima a Brasil}

En agosto de 1899, al recibir la notificación oficial de la existencia de peste en Oporto, el gobierno brasileño tomó medidas de inmediato para defender el país contra la invasión. Estableció que todos los buques que habían salido de los puertos portugueses, así como también del puerto español de Vigo, a partir del 1 de agosto, se someterían a una cuarentena durante 20 días y

9. Cruz, Oswaldo G. A Peste. In Opera Omnia. Río de Janeiro: Tipografía del Instituto Oswaldo Cruz; 1906.

10. Cukierman, Henrique Luiz. Viagens a Santos. História, Ciência Saúde - Manguinhos. 1998; 5 (1), p. 35-56. 
estarían sujetos a una desinfección estricta. Estas medidas se ampliaron, mediante resolución del 16 de agosto, a los puertos españoles de La Coruña, Santander y Bilbao.

Sumado a esto, el presidente del Estado de Sao Paulo, preocupado con el puerto de Santos, el segundo en importancia en el país y cuya protección era de su competencia, aumentó el personal de la Comisión Sanitaria de la ciudad y colocó en marcha «todas las medidas de vigilancia sanitaria recomendadas por la ciencia» ${ }^{11}$ con una estricta vigilancia de los buques de procedencia sospechosa.

El 5 de septiembre, el gobierno tuvo conocimiento por medio de un «documento oficial de origen fuera de sospecha» ${ }^{12}$, de la existencia de la peste en Porto desde el día 4 de junio. Esto significaba que la enfermedad había sido notificada tarde. Se concluye así que durante 70 días la peste había tenido pasada libre en los puertos brasileños.

A mediados de septiembre, el gobierno fue informado de la existencia de la peste en Paraguay. La noticia de la aparición de la peste en Paraguay «explotó como una amenaza asombrosa» ${ }^{13}$. No se trataba de una amenaza de la llegada de la peste sólo por mar sino también por tierra a través de las fronteras de Paraná y Mato Grosso, extensas y sin protección, lo que aumentó considerablemente el temor generado por la plaga en Portugal, porque la defensa por tierra, según el informe, fue «siempre precaria en sus efectos» ${ }^{14}$.

Esta situación excepcional exigiría medidas también excepcionales. Así, por decreto del 21 de septiembre de 1899, los puertos brasileños se cerraron a las embarcaciones procedentes de Paraguay. El ministro reconoció la medida como violenta, pero justificable, ante una amenaza tan grande.

Ambos gobiernos, de Mato Grosso en septiembre y de Paraná en octubre, solicitaron la intervención del gobierno federal, dejando a la Dirección General de Salud Pública (DGSP) responsable por la defensa de la frontera. Además de eso, se estableció un cordón sanitario militar en los

11. Mensaje enviado al Congreso del Estado, el 7 de abril de 1900, por el Dr. Fernando Prestes de Albuquerque, Presidente del Estado de Sao Paulo. São Paulo: Tipografia do Diário Oficial; 1900, p. 144.

12. Informe presentado al presidente de la República de los Estados Unidos de Brasil por el Dr. Epitácio Pessôa, Ministro de Justicia y Negocios Interiores, en marzo de 1900. Río de Janeiro: Imprensa Nacional; 11900, p. 350.

13. Informe, n. 12, p. 352.

14. Informe, n. 12, p. 350. 
puntos menos resguardados de las fronteras. Sin embargo, la epidemia de peste en Paraguay se circunscribió a la ciudad de Asunción, no extendiéndose a otros lugares de ese país, siendo suficientes las medidas sanitarias ya implementadas.

Además de las precauciones tomadas, el gobierno brasileño se comprometió a almacenar el suero anti peste de Yersin $^{15}$ en caso de surgir algún enfermo en el país. Encargó el suero a los laboratorios europeos, pero debido a la epidemia de peste en Porto, sólo los Institutos Pasteur y de Messina podrían proporcionar el suero e incluso así en cantidad escasa. Había un cuestionamiento en lo que se refería a la eficacia del suero importado debido al gran intervalo entre su producción y su uso, incluso si se conservaba adecuadamente. En este momento, hubo un intento frustrado de fabricar en el país el suero y la vacuna contra la peste, según concluye el informe:

«El director general de la salud pública había obtenido, en el Instituto Experimental de Higiene de Montevideo, los cultivos del bacilo de la peste traídos de Paraguay y en un estado de alta virulencia, con los cuales intentó preparar entre nosotros, tanto el suero curativo como la vacuna según el método de Haffkine; pero las dificultades que se le dieron aquí fueron tales que lo forzaron a desistir de traerlo y a esperar que las diligencias de nuestros agentes diplomáticos en Europa pudiesen surtir el efecto deseado y recibiésemos el suero tan insistentemente pedido» ${ }^{16}$.

El 14 de octubre, el gobierno brasileño recibió una noticia preocupante: se había producido un resurgimiento de la epidemia de la peste en porto. Ese mismo día, se emitió una ordenanza prohibiendo «la entrada en los puertos nacionales de toda y cualquier mercancía embarcada en Leixões» ${ }^{17}$. Fue una decisión difícil que hería los intereses económicos de Portugal y Brasil, dado el intercambio comercial existente entre ambos países. Sin embargo, según el ministro, no hubo duda al tomar esa medida.

En un mensaje del Presidente del Estado de Sao Paulo sobre el año 1899 se relata que a principios de septiembre se notó la presencia de ratas muertas en varios puntos de la costa y en mayor cantidad en los almacenes

15. El suero anti peste de Yersin era el único medio preventivo y curativo eficaz, hasta entonces, contra la enfermedad.

16. Informe, n. 12, p. 352.

17. Informe, n. 12, p. 353. 
de los muelles y en las calles aledañas. Esta mortandad de ratas era ya un indicio de la presencia de la peste bubónica.

Cabe destacar la importancia de Santos para la economía brasileña, lugar por donde entraban y salían mercancías y personas en grandes cantidades y por donde drenaba principalmente la producción de café, que, a partir de la década de 1840, lideraba, indiscutiblemente, las exportaciones brasileñas.

\section{El puerto de Santos}

Santos fue el escenario de un gran cambio en la segunda mitad del siglo XIX. De una aldea remota se convirtió en 1870 en un centro económico y su puerto pasó a ser el segundo puerto de exportaciones de café del país, necesitando obras de mejoras y modernización para hacer frente al volumen de operaciones de importación y exportación. Sólo para dar una idea del creciente movimiento de exportación de café, en sacos de 60 kilos, por el puerto de Santos se registró en el año 1870 un movimiento de 437.580 sacos; en 1880 fueron 1.804 .328 sacos; en 1890 se contabilizaron 2.952 .372 y en el año 1899 un total de $5.742 .362^{18}$.

Después de varios intentos sin éxito de reformas en el puerto de Santos, tanto privadas como del gobierno, así como debido a los problemas en el flujo de embarque y desembarque de mercancías, por presión de la Asociación Comercial de Santos ${ }^{19}$, el gobierno imperial hizo una oferta pública para atraer inversores privados. Cándido Gaffrée y Eduardo Palassim Guinle ganaron la oferta pública y llegaron, en 1892, a transformar su empresa Gaffrée \& Guinle en la Compañía Docas de Santos, una de las mayores empresas del país ${ }^{20}$.

El puerto de Santos era, también, la puerta de entrada al creciente número de inmigrantes europeos que venían a sustituir la mano de obra

18. Almanaque de Santos, editado al final de 1970 por Ariel Editora e Publicidade de Santos/SP. En esa publicación, las páginas 170 a 300 forman una edición conmemorativa del centenario de la Asociación Comercial de Santos. Consultado en www.novomilenio.inf.br/santos/ h0315d05.htm.

19. La Asociación Comercial de Santos fue creada el año 1870 y representaba las grandes compañías de importación y exportación. Sus presidentes fueron, en su mayoría, hacendados productores de café.

20. Honorato, Cezar. O polvo e o porto: a Cia. Docas de Santos (1888-1914). São Paulo: Hucitec; 1996. 
esclava, hasta entonces utilizada en las plantaciones de café. Esta afluencia de inmigrantes tomó impulso a partir del último cuarto del siglo XIX.

El fenómeno de la inmigración de las poblaciones europeas para las Américas se inserta en el contexto de un enorme desplazamiento transoceánico de poblaciones que se produjo en toda Europa desde mediados del siglo XIX. Este fenómeno tuvo como principales condicionantes, por una parte, la fuerza de atracción ejercida por la perspectiva de enriquecimiento en nuevas áreas y, por otro, la fuerza de repulsión ejercida por la pobreza, las dificultades de sobrevivencia y superpoblación en los países de origen, causada por una crisis económica por la cual pasó Europa en este período ${ }^{21}$. En lo que se refiere al movimiento de inmigración para Brasil, el Estado de Sao Paulo fue privilegiado. Desde el año de 1887 hasta 1900, se estima que alrededor del $61 \%$ de los inmigrantes que entraron a Brasil tuvieron el Estado de Sao Paulo como destino. En 1901, por ejemplo, Brasil recibió 85.306 inmigrantes, de los cuales 71.782 se dirigieron para Sao Paulo ${ }^{22}$ :

«[... ] cuando se abolió la esclavitud, aunque hubiera un potencial grande de mano de obra libre, éste no fue totalmente expropiado y no sufría presiones económicas suficientes para transformarse en fuerza laboral remunerada. El hacendado se volvió, entonces, para el exterior en busca de los brazos que necesitaba» ${ }^{23}$.

Era necesario asegurar la producción y la exportación de café. En ese momento, la transformación en las relaciones de producción agro exportadora, cuya mano de obra esclava se volvía condenable, requería mano de obra libre para su mantención y expansión. El Estado de Sao Paulo, que había ganado supremacía sobre Río de Janeiro como productor de café y cuya exportación se hacía por Santos a partir de 1870, comenzó a subsidiar la inmigración, así como lo hará el gobierno imperial a partir de la década siguiente $^{24}$. En 1886, se estableció la Sociedad Promotora de la Inmigra-

21. Petrone, Maria Tereza Schorer. Imigração. In: História Geral da Civilização Brasileira, sob a direção de Sérgio Buarque de Holanda, O Brasil Republicano. São Paulo: Difel; 1985, tomo III.

22. Petrone, n. 21, p.103.

23. Franco, Maria S. C. Organização Social do trabalho no período colonial. In: Paulo Sérgio Pinheiro, org. Trabalho Escravo, Economia e Sociedade. Río de Janeiro: Paz e Terra; 1984, p. 187.

24. Arias Neto, José Miguel. Primeira República: economia cafeeira, urbanização e industrialização. In: Jorge Ferreira y Lucilia de Almeida Neves Delgado. O tempo do liberalismo excludente: da Proclamação da República à Revolução de 1930. Río de Janeiro: Civilização Brasileira; 2003 (O Brasil republicano, v. 1). 
ción a iniciativa de Antonio de Queiroz Telles que en la época, además de hacendado, ejercía la presidencia de la provincia de Sao Paulo. Esta sociedad tenía por finalidad contratar y subvencionar la venida de inmigrantes con el apoyo financiero del gobierno de la provincia, proporcionando el pasaje de barco y el transporte ferroviario hasta las plantaciones de café ${ }^{25}$. Esta política de inmigración fue asumida por la República, reforzando la importancia de Santos.

\section{La peste llega a Brasil}

El 15 de octubre, aparecieron en Santos «los casos de una enfermedad grave, de sintomatología extraña y similar a la peste bubónica», principalmente por la presencia de importante adenitis. La investigación de estos casos fue hecha por Adolfo Lutz y Vital Brasil, director y asistente del Instituto Bacteriológico de Sao Paulo, respectivamente. Los dos investigadores utilizaron los entonces aún recientes conceptos obtenidos de los descubrimientos de Pasteur y concluyeron que se trataba de la peste bubónica. Así se constituyó, probablemente, la primera investigación realizada en el país de un brote de enfermedad desconocida que utilizó las nuevas bases microbiológicas entonces recién descubiertas.

Notificada la peste en Santos, el Ministerio de Justicia y Negocios Interiores emitió ordenanza cerrando los puertos brasileños a todas las embarcaciones provenientes de Santos a fin de limitar la epidemia, así como también comunicó internacionalmente la existencia de la peste en el territorio de Brasil. Santos, en cuarentena, generó intenso debate político y reacciones por el daño social y económico producido por esta medida.

El director de la DGSP, Nuno de Andrade, dirigió oficio al gobierno describiendo la situación sanitaria de los estados brasileños y, «juzgándose profundamente herido por el infortunio de la ciudad de Santos, como funcionario y como brasileño», solicitaba exoneración del cargo. Recordaba que en los 70 días anteriores a la notificación de la peste en Porto, los puertos brasileños quedaron desprotegidos, transitando por ellos, tal vez, mercancías contaminadas. ${ }^{26}$ 
El gobierno no aceptó la dimisión del director de la DGSP y, por considerar la situación de extrema gravedad, decidió enviar un bacteriólogo a Santos para realizar estudios que confirmaran o refutaran el diagnóstico de peste. Así fue designado el Dr. Oswaldo Cruz, recién llegado del Instituto Pasteur de París después de tres años de especialización en bacteriología. Al mismo tiempo, el director de Salud Pública designó a uno de sus asistentes, el Dr. Pereira das Neves, para investigar el origen de la peste en Santos y «examinar la regularidad del funcionamiento de los aparatos y dispositivos sanitarios al servicio de las autoridades de estado» ${ }^{27}$.

\section{Las investigaciones de los representantes de DGSP}

Las investigaciones epidemiológicas de Pereira das Neves identificaron dos episodios de mortandad de ratas en la ciudad: una a finales de julio y otra en la segunda quincena de septiembre. La conclusión fue que no se había producido la destrucción deliberada de las ratas y que la mortandad respondía a la existencia de una enfermedad contagiosa entre esos animales. Entre un brote y otro hubo una gran demanda en la consulta médica de la ciudad de adultos y niños que presentaban adenitis de la forma benigna, y otros que presentaba bubones. Sin embargo, el diagnóstico diferencial comprendió entre la fiebre perniciosa linfática y la fiebre amarilla ${ }^{28}$.

Estos hallazgos llevaron a la administración sanitaria local a realizar exámenes bacteriológicos en ratas, los cuales dieron resultados negativos. Cabe señalar que si un resultado positivo es una clara demostración de la existencia de la plaga, el resultado negativo no excluye, en definitiva, este diagnóstico.

Oswaldo Cruz, con su estilo pasteuriano ${ }^{29}$, llegó a Santos la noche del 23 de octubre, dirigiéndose inmediatamente al Hospital de Aislamiento, donde instaló un laboratorio con material cedido por Lutz y Vital Brasil, mientras esperaba su propio equipo que llegó unos días más tarde. Examinó

\footnotetext{
27. Informe, n. 12, p. 355.

28. Cruz, Oswaldo G. A Peste. In: Opera Omnia. Río de Janeiro: Tipografia del Instituto Oswaldo Cruz; 1906.

29. Cukierman, n. 10, p. 35-56. En este artículo, Cukierman analiza tres aspectos que conforman el estilo pasteuriano: no tratar directamente a los enfermos; a pesar de estar dentro del hospital, permanecer en su laboratorio; la instalación del laboratorio con equipos propios.
} 
minuciosamente a fondo cinco pacientes, pero ninguno de ellos «era un buen ejemplar para el estudio bacteriológico ${ }^{30}$ o porque estaban convalecientes o porque habían sido sometidos a tratamiento con el suero de Yersin. Uno de ellos, de acuerdo a Oswaldo Cruz, podría proporcionar el material para estudio. Se trataba de João Fonseca, de 14 años de edad, quien había caído enfermo el 20 de octubre y había dado entrada en el Hospital de Aislamiento el día anterior a las 15 horas con fiebre, dolores de cabeza e ingurgitación dolorosa de los ganglios linfáticos inguinales de ambos lados. Con el examen bacterioscópico directo no se llegó a un resultado satisfactorio y fue necesario nueva muestra en los ganglios del paciente para inoculación en los animales. El resultado del examen del conejillo de Indias reveló un número poco considerable de bacilos (coccobacilos) y murió días después de una enfermedad cuya evolución fue similar a la peste bubónica.

El segundo paciente examinado, de 12 años de edad, fue ingresado en el Hospital de Aislamiento en la noche del 24 de octubre con escalofríos, dolores de cabeza, fiebre e ingurgitación dolorosa de los ganglios inguinales y crurales derechos. Oswaldo Cruz describe las técnicas bacteriológicas utilizadas en el examen de ese paciente - tanto de forma bacterioscópica directa como en conejillos de Indias - y el resultado mostró la presencia de numerosos cocobacilos. El conejillo de Indias y el paciente murieron con todos los síntomas y las lesiones que se describe en la septicemia pestosa.

Oswaldo Cruz estableció como resultado de sus estudios:

1. Del organismo de los enfermos afectados por la molestia epidémica reinante en Santos se aisló un cocobacilo de morfología y biología perfectamente determinadas y característica.

2. En la taxonomía bacteriana, el coccobacilo aislado de los enfermos de Santos corresponde a la especie descrita por Kitasato y Yersin como productora de la peste bubónica.

3. Los caracteres clínicos y epidemiológicos de la enfermedad que brama en Santos se encuadran en los moldes clásicos de la peste bubónica» ${ }^{31}$.

Y concluye: «La enfermedad reinante en Santos es la peste bubónica».

30. Informe acerca de la molestia reinante en Santos, presentado por Oswaldo Cruz al Ministro de la Justicia y Negocios. In: Omnia. Río de Janeiro: Imprensa Nacional; 1900, p. 325.

31. Informe, n. 30, p. 331-332. 
Oswaldo Cruz vio en ese momento la oportunidad de crear un instituto sueroterápico, o mejor, institutos sueroterápicos en el país, y la configuración de este nuevo espacio significaría «la demarcación de un territorio de conocimiento» ${ }^{32}$. La presencia de la plaga en el país justificaba plenamente la construcción de estos institutos para producción del suero contra la peste. Indiscutiblemente reconocida la presencia de la peste en Santos, fue necesario desarrollar e implementar una estrategia de acción. Las medidas adoptadas por el gobierno de São Paulo para combatir con energía la epidemia en su origen fueron el aislamiento obligatorio de los enfermos, la reclusión de sus familias, la desinfección de los hogares, la restricción de las comunicaciones con las localidades sin epidemia y la creación de un cordón sanitario, fiscalizando las carreteras, los registros de los recién llegados y vigilancia médica de los fugitivos y transeúntes ${ }^{33}$. No obstante, la peste en Santos no se cubría del carácter devastador de las epidemias de la Edad Media ya marcadas en el imaginario colectivo, lo que causaba dudas sobre su diagnóstico, conforme señala en la ocasión Epitácio Pessoa, ministro de Justicia y Negocios Interiores:

«Con ocasión de la aparición de la peste en Santos, no faltaron los impugnadores del diagnóstico formulado, no obstante, con la máxima seguridad científica, en virtud de la persuasión equivocada, aún no desarraigada en muchos espíritus de que la epidemia del Levante [peste bubónica] tiene la obligación de revestir la característica devastadora que las descripciones pavorosas de la Edad Media le imprimieron y como en las condiciones actuales de civilización y de cuidados higiénicos no se desarrolla con la misma intensidad de entonces, se confunde lo principal con lo accesorio y se niega el diagnóstico porque la extensión epidémica no realiza el tipo descrito en las crónicas» ${ }^{34}$.

En una carta enviada desde Río de Janeiro a su esposa, Laura das Chagas, el 8 de julio 1900, Cícero Ferreira, sanitarista de Minas Gerais, describe su trabajo para combatir la plaga, destacando el esfuerzo de las autoridades para contener la epidemia, haciendo referencia también a la poca importancia que la gente le daba a la enfermedad:

\footnotetext{
32. Cukierman, n. 10, p. 47.

33. Informe, n. 12, p. 357.

34. Informe presentado al presidente de la República de los Estados Unidos de Brazil por el Dr. Epitácio Pessôa, Ministro de Justicia y Negocios Interiores, en marzo de 1901, p. 313-314.
} 
«Aquí estoy purgando mis pecados, lejos de ti y de los hijos. La peste lo mismo. Son de tres a cuatro casos por día y hoy me consta que fue atacado un hijo del senador Generoso Ponce, habiendo sido confirmado el diagnóstico. Sin embargo, nadie aquí le está dando mucha importancia a la epidemia; (...) No pudiendo tomar providencias enérgicas, la epidemia tenderá a desarrollarse. Nuno de Andrade se mostró muy satisfecho con mi venida y puso a mi disposición los aparatos que necesitaba» ${ }^{35}$.

Por último, del 14 de octubre hasta el 28 de diciembre, fecha de la última entrada, fueron recogidos y atendidos en el Hospital de Aislamiento de Santos, 35 pacientes con fiebre, de los cuales 15 murieron, habiendo tenido alta 20 , representado un coeficiente de mortalidad de $42,85 \%$, porcentaje satisfactorio si miramos la letalidad de la peste negra que en otros tiempos había victimado $95 \%$ de los pacientes que la padecieron ${ }^{36}$.

El brote de peste en el puerto de Santos no mostró la mortalidad esperada de una epidemia de peste, como la que había asolado diferentes regiones de Europa en la Edad Media. Sin embargo, la baja intensidad del evento en Santos no calmó el temor de las autoridades nacionales de que nuevos eventos pudiesen confirmar sus temores de un contagio mortal, generalizado. Este ambiente de terrores, reales o imaginarios, fue providencial para científicos como Oswaldo Cruz, Adolfo Lutz y Vital Brasil que, deseosos de implementar en Brasil la producción del suero y de la vacuna contra la peste, veían en las futuras instituciones, encargadas de esta misión, la trinchera a partir de la cual podrían conducir, victoriosos, el combate por la fundación de la bacteriología en el país.

\section{La peste en Sao Paulo}

El enfrentamiento con la peste en Santos implicaba, también, evitar su propagación a otras ciudades. Se sabía que el Ferrocarril Central era el medio más rápido y preferido de comunicación entre Sao Paulo, Río de Janeiro y Minas Gerais. En ese sentido, los gobiernos, tanto en Río de Janeiro como en Minas Gerais, también tomaron medidas para evitar la invasión de la

35. Documento facilitado por la investigadora Rita de Cássia Marques, que custodia parte del acervo de Cícero Ferreira.

36. Mensaje enviado al Congreso del Estado, el 7 de Abr de 1900, por el Dr. Fernando Prestes de Albuquerque, Presidente del Estado de Sao Paulo. São Paulo: Tipografia do Diário Oficial; 1900, p. 144. 
plaga en sus territorios que consistían, principalmente, en la desinfección de los equipajes de los trenes provenientes de Sao Paulo, así como el aislamiento de los pasajeros sospechosos de estar con la peste.

Hasta principios de noviembre, estas fueron las principales medidas adoptadas en relación con el ferrocarril cuando entonces se diagnosticó el primer caso de peste en la capital del Estado de Sao Paulo en una residente de una choza, cerca de la estación de ferrocarril de la línea Sorocabana. Su casa fue completamente desinfectada y destruida ${ }^{37}$.

Con la aparición de este caso de peste en Sao Paulo, era necesario que nuevas acciones se implementaran a fin de evitar que la enfermedad se intensificase y se propagase por el estado e incluso ultrapasase sus fronteras en dirección, principalmente, a la Capital Federal. Por lo tanto, las principales medidas consistían en la receta clásica de la lucha contra las enfermedades epidémicas, a saber: vigilancia sanitaria, cuya tarea principal era encontrar los enfermos con la peste y desinfectar los posibles focos de la epidemia, aislar a los enfermos y los sospechosos de contaminación, desinfectar e incluso quemar casas y pertenencias de esas personas.

Aliada a todas estas acciones, la principal medida de la política sanitaria de combate a la plaga en la capital de la provincia de Sao Paulo fue la lucha contra las ratas. Desde los descubrimientos de Yersin, Kitasato y Simond, en la última década del siglo XIX, la transmisión de la enfermedad por la pulga de las ratas ya estaba comprobada. Sin embargo, aunque comprobada científicamente $^{38}$, no se había aplicado una política de lucha en gran escala contra las ratas. Teniendo en cuenta esta singularidad, el gobierno del Estado de Sao Paulo estructuró su estrategia de caza a las ratas en dos frentes, una de ellas ejecutada por los servicios sanitarios y otra por la población.

En la lucha contra las ratas, los servicios de salud se preocuparon de poner veneno en los drenajes de alcantarillado y galerías de aguas pluviales, desinfectar depósitos, casas y otras construcciones donde pudiesen existir lugares propicios para la reproducción de estos de roedores, enviar veneno para las ciudades del interior del Estado de Sao Paulo y retirar la basura de las calles ${ }^{39}$.

\footnotetext{
37. O Estado de São Paulo, 5 Nov 1899.

38. Delort, Robert. Que a peste seja do rato. In: Le Goff, Jacques. As doenças tem História. Lisboa: Editora Terramar; 1985, p. 111; Stepan, Nancy. Gênese e evalucão de Ciência brasileira. Río de Janeiro: Editora artenova; 1976, p. 68.

39. O Estado de São Paulo, 5 Nov 1899, p. 1.
} 
La población, a su vez, era incentivada a cazar a los animales. Los periódicos instaban a la población, en artículos llenos de metáforas bélicas, a luchar en esa importante «batalla». Un ejemplo de esto es el artículo del diario O Estado de São Paulo, publicado el 7 de noviembre, que así informa al público y a las autoridades:

«Guerra a las ratas, guerra constante, tenaz de exterminio. Es este el consejo, es esta la palabra de orden que la ciencia nos transmite y que nosotros transmitimos a las autoridades» ${ }^{40}$.

Además de los periódicos, el gobierno alentó a la población, mediante la distribución de panfletos, denominado «Instrucciones para el pueblo», informando sobre los peligros de la peste bubónica y la importancia de cazar las ratas para evitar la propagación de la enfermedad entre la población ${ }^{41}$. En el folleto Peste: matanza de las ratas, el Servicio Sanitario del Estado de Sao Paulo afirmaba que: «Para terminar con la peste es necesario mover una guerra a muerte a las ratas y a las pulgas, que son sus agentes más activos de la propagación ${ }^{42}$. El folleto sigue orientando, entre otras cosas, sobre el uso de la masa con veneno en los locales susceptibles de tener ratas y dentro de las casas, y que cualquier mortandad de ratas debe ser reportada a las autoridades sanitarias. Concluye diciendo que esas medidas defenderían la ciudad contra la terrible epidemia que la amenaza.

Por último, y lo que probablemente constituye el principal incentivo para la población, el gobierno pagaba por las ratas cazadas. Esta práctica funcionaría de la siguiente manera, según informó el 5 de noviembre $O$ Estado de São Paulo: «a partir de hoy, el Desinfectorio Central pagará a 300 reis $^{43}$ las ratas muertas» ${ }^{44}$. Para ayudar en esta operación, el gobierno repartió también a la población trampas y veneno.

Estos incentivos tienen resultados inmediatos. El 4 de noviembre de 1899, se incineraron $417^{45}$ ratas y, al día siguiente, cuando la ley entró en

\footnotetext{
40. O Estado de São Paulo, 7 Nov 1899, p. 1.

41. O Estado de São Paulo, 11 Nov 1899, p. 1.

42. Serviço Sanitário do Estado de São Paulo. Peste: matança dos ratos. São Paulo: Escola Tipográfica Salesiana; 1899, p. 1 e 2. Este folleto está escrito en portugués, italiano, alemán, inglés y francés.

43. Es interesante notar que cuando las ratas comenzaron a ser cazadas en Río de Janeiro, en setiembre de 1903, se estableció el mismo valor de 300 reis para cada animal muerto.

44. O Estado de São Paulo, 5 Nov 1899, p. 1.

45. O Estado de São Paulo, n. 40, p. 1.
} 
vigor, fueron muertas 961 ratas $^{46}$. Ese día fue realmente inusual, pues el promedio durante el mes de noviembre fue de 600 animales muertos por día, totalizando 14.000 ratas incineradas al final del mes.

A pesar de inusitada, la estrategia dio resultados. En noviembre, los diarios informaron de la aparición de un nuevo caso de peste en la ciudad ${ }^{47}$. En ese mismo periodo, se diagnosticaron en Santos 32 casos, siendo 11 diagnosticados como fatales ${ }^{48}$. Durante el mes de diciembre, la situación continuó igual, ocurriendo solamente un caso de peste al final del mes. Incluso con pocos casos, las autoridades del Estado de Sao Paulo buscaron intensificar la campaña de caza de ratas pasando a comprarlas a 400 reis $^{49}$.

Nuevos casos esporádicos de peste surgieron en la ciudad de Sao Paulo al comienzo de 1900 sin generar una epidemia, al contrario de lo que ocurrió hasta el año de 1906 en Río de Janeiro. El éxito de Sao Paulo, en relación a la Capital Federal, se debió, principalmente, a la campaña de caza a las ratas, aliada a otras políticas sanitarias que, solamente a partir de 1903, serían utilizadas por Oswaldo Cruz en Río de Janeiro, también con resultados satisfactorios.

Además de estas medidas sanitarias, el gobierno del Estado de Sao Paulo también buscó suplir la falta de suero anti peste en el caso de que una epidemia fuera a estallar en la ciudad. Por consejo de los científicos involucrados con el diagnóstico y combate a la peste en Santos, se decidió crear un instituto sueroterápico en Sao Paulo, vinculado al Instituto Bacteriológico. Los periódicos siguieron, con la misma intensidad, las noticias sobre el nuevo instituto. Si el 6 de noviembre no había una definición de la ubicación del Instituto Sueroterápico de Sao Paulo, tres días después ya se anunciaba la compra de la finca Butantan para este fin. El 15 de noviembre, se publica que «el Dr. Vital Brazil comienza experimentos de inoculación de la plaga en los caballos», y se anunciaba en los periódicos cada nuevo experimento llevado a cabo en el instituto.

Vital Brazil asumió la dirección del Instituto Sueroterápico de Sao Paulo, pero él no actuó de forma aislada. Además de informes y comunicaciones en reuniones científicas, mantenía correspondencia con Oswaldo Cruz a través de cartas personales que demuestran una preocupación común por

\footnotetext{
46. O Estado de São Paulo, 6 Nov 1899, p. 1.

47. O Estado de São Paulo, 12 Nov 1899, p. 1.

48. O Estado de São Paulo, 5 Dic 1899, p. 1.

49. O Estado de São Paulo, 30 Dic 1899, p. 1.
} 
el proyecto de sus institutos ${ }^{50}$. En carta dirigida a Oswaldo Cruz, el 20 de noviembre de 1899, Vital Brazil expresa sus ideas y preocupaciones con sus experiencias en el día a día de su instituto, según trechos aquí destacados:

«(...) Hice experimentos, en pequeños animales, ratas y conejillos de Indias, con los cultivos que traje de Santos. Resultados magníficos. Aún no concluí, sin embargo, el estudio de los cultivos (...). Como ya debes saber, el Gobierno adquirió la hacienda de Butantan, destinándola para el Instituto Sueroterápico del Estado. Supe por Ribas, que viste y apreciaste mucho aquel local para la instalación del Instituto, lo que me agradó mucho por la autoridad de tu opinión. Soy el encargado de la preparación del serum y quizás de la instalación del Instituto. No sé si podré con tamaña responsabilidad. Empecé la inmunización de 4 caballos, por inyección intravenosa de cultivos muertos, hasta conseguir una caballeriza - enfermería para los caballos con peste. Usaremos entonces cultivos virulentos (...). La inyección en los 4 caballos corrió bien. Presentaron alguna reacción que no duró mucho tiempo. Hoy, entre tanto, al hacer la $2^{\text {a }}$ inyección perdimos súbitamente uno de los animales, a lo que parece, de una embolia. ¿Cómo va tu Instituto? Cuéntame tus esperanzas y auxíliame con tus sabios consejos. Te pido, con el mayor empeño, que con la posible brevedad, me mandes la relación completa de los aparatos, pequeños objetos y todo el material necesario para la instalación de un Instituto sueroterápico» ${ }^{51}$.

El Gobierno de Minas Gerais, preocupado de poner el territorio del estado al abrigo de la invasión de la enfermedad, tomó las medidas que el caso exigía, dando instrucciones a los inspectores de higiene en diversos municipios, dirigiéndose a los presidentes de la cámaras y agentes ejecutivos municipales para que las medidas sanitarias se pusieran en práctica y, por último, estableciendo puestos de desinfección en diversos puntos.

Aunque el gobierno de Sao Paulo inspeccionase todos los pasajeros que salieron de la capital del estado, el gobierno de Minas Gerais trató de proteger la región sur de su estado y el Triángulo, construyendo estaciones de desinfección equipadas con una estufa y un pulverizador en Passa Quatro (primera estación del estado de Minas Gerais de la línea férrea Minas-Río que se conectaba a la Central en la estación Cruzeiro), Eleutério

50. Oswaldo Cruz, en esa misma época, había asumido la dirección del Instituto Sueroterápico Municipal, en la Hacienda Manguinhos, en Río de Janeiro.

51. Dossiê Vital Brazil - 1899/1914. Acervo Biblioteca Virtual Oswaldo Cruz, Fundação Oswaldo Cruz, Casa de Oswaldo Cruz, DAD. 
(correspondencia con el ramal de Itapira, viniendo de la Mogiana), Cascavel (entroncamiento de un ramal que iba de la Mogiana a Poços de Caldas), Mococa (punto final del ramal viniendo de la Mogiana) y Uberaba (al final del tronco de la Mogiana). Para la construcción de los puestos que quedaban en territorio del estado de Sao Paulo, como los de Cascavel y Mococa, se firmó un acuerdo entre los gobiernos de los dos estados ${ }^{52}$.

Los trabajos del sanitarista de Minas Gerais, Cícero Ferreira, en la Estación Central de Río de Janeiro, dieron los efectos deseados, pues no se registró ningún caso de peste bubónica, en Minas Gerais, en aquel periodo, a pesar de los pronósticos alarmistas de la prensa de Río de Janeiro en el sentido de que era inevitable la llegada de la enfermedad al estado.

\section{Comentarios finales}

En la lucha contra la plaga, es posible concebir las estrategias públicas y las acciones implementadas como un todo articulado, cuyas principales medidas consistieron en el aislamiento de los enfermos o sospechosos de estar infectados y en la desinfección de sus casas y sus bienes. Además de eso, en la asistencia al paciente, se aplicaba el suero y la vacuna contra la peste. Tal política de salud no era una novedad, pues ya se venía aplicando a otras enfermedades. Lo que el combate a la peste trajo de novedad fue la caza a las ratas, es decir, el combate al vector de la enfermedad.

Hasta el episodio de la peste bubónica, las acciones en el campo de la salud pública en el país se estaban llevando a cabo de forma aislada y puntual. La epidemia plantea, por primera vez, una acción conjunta de varios estados para combatirla y evitar su propagación y, más que eso, permite la creación en 1899, del Instituto Butantan de Sao Paulo y del Instituto Sueroterápico Municipal en la Hacienda Manguinhos en Río de Janeiro, ambos con el objetivo de producir sueros y vacunas contra la peste y el establecimiento de una estandarización de estos productos de acuerdo con las condiciones del país.

52. Marques, Rita de Cássia. E a peste não chegou a Minas Gerais. In: IX Congresso Brasileiro de História da Medicina, 2004, Río de Janeiro. São Paulo: Sociedade Brasileira de História da Medicina: 2004, p. 25. 
Por lo tanto, Oswaldo Cruz, en Río de Janeiro, con la creación del Instituto de Manguinhos y Vital Brazil, en Sao Paulo, con la creación del Instituto Butantan consiguieron lo que parecía ser una estrategia para consolidar en el país la medicina experimental, basada en los conceptos de la bacteriología. 
